\title{
PACIENTE COM INSUFICIÊNCIA RENAL CRÔNICA EM TRATAMENTO HEMODIALÍTICO: ATIVIDADE EDUCATIVA DO ENFERMEIRO
}

Claudia Bernardi Cesarino*

Lisete Diniz Ribas Casagrande**

CESARINO, C.B.; CASAGRANDE, L.D.R. Paciente com insuficiência renal crônica em tratamento hemodialítico: atividade educativa do enfermeiro. Rev.latino-am.enfermagem, Ribeirão Preto, v. 6, n. 4, p. 31-40, outubro 1998.

O objetivo deste estudo foi contribuir para o conhecimento da atividade educativa do enfermeiro com paciente renal crônico em tratamento hemodialítico, proporcionando uma melhoria da sua qualidade de vida, através da educação conscientizadora. Os sujeitos desse estudo eram oito pacientes renais crônicos, sendo quatro do sexo feminino e quatro do sexo masculino, com idade variando entre 17 a 63 anos de idade. A trajetória metodológica foi a da pesquisa-ação, e a coleta de dados sobre situações significativas foi realizada através da observação participante. A interpretação dos dados relacionouse com o referencial proposto por PAULO FREIRE, isto é, a análise dos temas geradores. Os dados foram selecionados e codificados em seis temas geradores: Insuficiência Renal Crônica (IRC), Causas da IRC, Tratamento Hemodialítico, Limitações e Possibilidades do Renal Crônico em Tratamento Hemodialítico, Transplante Renal e Apoio Familiar. Os Círculos de Discussão desenvolveram-se segundo o Método Pedagógico de PAULO FREIRE. Após essa fase, foram constatadas mudanças satisfatórias na qualidade de vida dos pacientes renais crônicos participantes do processo ensino-aprendizagem. Isso permite concluir que houve desenvolvimento da consciência ingênua para a crítica em relação à sua situação, pois ocorreram transformações na sua realidade.

UNITERMOS: enfermagem, educação, hemodiálise

\section{INTRODUÇÃO}

A insuficiência Renal Crônica e o tratamento hemodialítico, provoca uma sucessão de situações para o paciente renal crônico, que compromete o aspecto não só físico, como psicológico, com repercussão pessoais, familiares e sociais. Na convivência com estes pacientes, ficou clara a importância da intervenção da enfermagem em busca de solução nas limitações provocadas pela IRC e o tratamento, sendo necessário um reaprender a viver, de uma maneira mais humana.

Para BARBOSA (1993), o doente renal crônico vivência uma brusca mudança no seu viver, convive com limitações, com o tratamento doloroso que é a hemodiálise, com um pensar na morte, mas convive também com a possibilidade de submeter-se ao transplante renal e a expectativa de melhorar a sua qualidade de vida. Conseqüentemente, LIMA (1989) refere que os pacientes renais crônicos acabam se tornando desanimados, desesperados e, muitas vezes, por estas razões ou por falta de orientação, acabam abandonando o tratamento ou não dando importância aos cuidados constantes que deveriam ter. É necessário estimular suas capacidades, para se adaptarem de maneira positiva ao novo estilo de vida e assumirem o controle de seu tratamento

GORRIE (1992) relata que a educação do paciente renal é um compromisso do enfermeiro, e este deve ter orgulho disso. Diz ainda que os enfermeiros não são treinados para ser professores, por isso está sendo discutido o processo ensino-aprendizagem no curriculo de enfermagem em nefrologia. De acordo com minha própria experiência, percebo que, entre os profissionais de saúde, o enfermeiro é um dos elementos que atuam de modo mais constante e mais próximo dos pacientes. É este profissional, que através da assistência, deve planejar intervenções educativas junto aos pacientes, de acordo com avaliação que realiza, numa tentativa de ajudá-los a reaprender a viver nessa realidade.

PHILLIPS et al. (1983) relatam que é essencial a ação educativa com paciente renal crônico, para descobrir maneiras de viver dentro dos seus limites, de forma que não seja contrária ao seu estilo de vida e que

\footnotetext{
* Mestre em Enfermagem e Professora do Curso de Graduação em Enfermagem da FAMERP, São José do Rio Preto

** Professora Doutora da Faculdade de Filosofia, Ciências e Letras de Ribeirão Preto da Universidade de São Paulo
} 
consiga conviver com a doença e com o tratamento hemodialítico. Para que os pacientes assumam os cuidados e controle do esquema terapêutico, é necessário identificar as suas necessidades, auxiliá-los a se sentirem responsáveis e capazes de cuidarem de si mesmos.

A partir destas observações, decidi investigar o papel educativo do enfermeiro junto pacientes com IRC, em tratamento de hemodiálise, verificando as possibilidades e os limites de uma ação educativa que permita a conscientização dos pacientes quanto à sua situação, tendo em vista uma ação transformadora dessa realidade. Optamos pelo referencial teórico de PAULO FREIRE(1992), pois assim, os pacientes poderão ampliar sua consciência da situação vivenciada, sua capacidade de optar e se relacionar com o mundo em que vivem.

\section{OBJETIVOS}

2.1. Identificar as necessidades de aprendizagem e conhecimentos prévios dos pacientes.

2.2. Identificar, através da observação participante, os temas geradores para o desenvolvimento de um trabalho educativo dirigido a pacientes com IRC em hemodiálise. 2.3. Elaborar, com os pacientes renais crônicos, um plano de ensino, de acordo com os temas mais evidenciados na observação participante.

2.4. Implementar o plano de ensino elaborado, favorecendo a conscientização destes pacientes sobre os problemas observados e detectados da situação referida. 2.5. Avaliar o plano de ensino implementado com os pacientes.

\section{MARCO CONCEITUAL}

Para atingir os objetivos propostos, optei pela pesquisa-ação, em uma abordagem qualitativa, para a compreensão do paciente com IRC em hemodiálise e da realidade vivenciada por este, buscando assim a elaboração e implementação de um plano de ensino que favoreça a conscientização deste paciente.

Para THIOLLENT (1988), a pesquisa-ação é um tipo de pesquisa social com base empírica, em que os pesquisadores e os participantes representativos da situação ou do problema estão envolvidos de modo cooperativo ou participativo. O mesmo autor relata que a pesquisa-ação necessita de um referencial teórico para ter sentido, e ressalta que a mediação teórico-conceitual permanece operando em todas as fases da pesquisa.

Adotei o modelo da educação conscientizadora, pois propicia o desenvolvimento do homem como um todo, tornando-o agente de sua própria transformação. Assim,
FREIRE (1993) elimina de sua pedagogia, a concepção tradicional da educação, que são métodos centrados na autoridade do educador, o qual detém o saber. Propõe uma educação conscientizadora, que parte da experiência e da percepção do educando.

A educação conscientizadora de FREIRE(1992) se realiza no chamado "Círculo de Cultura", formado por um grupo de pessoas que se reúne para aprender a ler e escrever, ou para discutir seu trabalho, a realidade local ou nacional. Assim, em lugar da escola, diz "Círculo de Cultura". Em lugar de professor, "coordenador de debates". Em lugar de aluno, o "participante de grupo". Em lugar dos pontos e de programas alienados, a "programação compacta e codificada" em unidades de aprendizado.

Ao buscar o embasamento na literatura brasileira, não encontrei trabalhos que abordam a atividade educativa do enfermeiro com pacientes portadores de IRC em tratamento hemodialítico. Ora, o paciente renal crônico é um ser humano, exposto a valores culturais e sociais. Partindo desse princípio, considero pertinente a utilização da educação concientizadora, visto que a mesma parte da vivência dos pacientes, criando oportunidades de desenvolver e aperfeiçoar a sua capacidade de compreender criticamente a realidade em que estão inseridos.

\section{METODOLOGIA}

\subsection{O processo de coleta de dados}

A pesquisa-ação facilita o envolvimento do pesquisador numa prática participativa com os pacientes portadores de IRC em hemodiálise. Como técnica de coleta de dados, foi escolhida a observação participante, porque ajuda o pesquisador na interação com os sujeitos da pesquisa, no próprio ambiente deles. CHIZZOTTI (1991) coloca que a observação participante é obtida por meio de contato direto do pesquisador com o fenômeno observado, para recolher as ações dos atores em seu contexto natural, a partir de sua perspectiva e seus pontos de vista. Segundo MINAYO (1994), “a observação participante pode ser considerada parte essencial do trabalho de campo na pesquisa qualitativa."

No presente estudo, os pacientes renais crônicos foram observados segundo orientação de DOMINGUES (1985), durante o tratamento hemodialítico, na unidade de hemodiálise. Para o registro, foram feitos anotações no diário de campo, imediatamente após o término da observação. DOMINGUES (1985) considera as seguintes categorias na observação do contexto em estudo:o espaço, as atividades que as pessoas desempenham, a sequência 
e duração das ações, as pessoas envolvidas, as informações observadas e as emoções expressas ou percebidas. Essas categorias ajudaram-me na compreensão da realidade e orientaram-me na investigação.

Após o levantamento das questões dos pacientes renais crônicos em hemodiálise, foi elaborado e implementado a atividade educativa do enfermeiro com o grupo de pacientes renais crônicos. A atividade educativa foi realizada no anfiteatro do Hospital Escola, nos meses de abril e maio de 1995 todas as quintas-feiras e no horário das doze horas as treze horas e trinta minutos. Essa atividade educativa, com a autorização do referido grupo foi filmada e o conteúdo das discussões foi transcrito, posteriormente, para a realização da análise temática.

\subsection{O local da pesquisa}

O estudo foi realizado em um Hospital Escola de médio porte de uma cidade do interior do Estado de São Paulo, que presta assistência hospitalar e ambulatorial em várias especialidades médicas, dedicando-se também ao ensino e à pesquisa. $\mathrm{O}$ ambiente específico, onde se realizou este estudo, foi a Unidade de Hemodiálise, que é localizada no andar térreo de um prédio de sete andares, ficando perto dos serviços de laboratório, da unidade de emergência e do serviço de radiologia.

\subsection{Escolha do grupo a pesquisar}

Já trabalhava juntamente com outros profissionais, na assistência a um grupo de pacientes renais crônicos que se submetia ao tratamento de hemodiálise, todas as terças, quintas-feiras e aos sábados, no referido HospitalEscola, no período da manhã.

Em novembro de 1993, juntos, profissionais de saúde e membros do grupo, decidimos interromper temporariamente o trabalho do grupo, por não estarem os participantes compreendendo os temas discutidos, e conseqüentemente, os objetivos propostos não estavam sendo contemplados.

Quando fui escolher os pacientes renais crônicos para este estudo, escolhi pois o grupo que tinha interrompido o trabalho anterior, por já possuir uma aproximação e maior interação com os participantes do referido grupo. E como já nos conhecíamos há algum tempo, iniciei a atividade de coleta de dados no mês de agosto de 1994, pois podia considerar-me inserida no contexto hospitalar, local da investigação.

A pesquisa-ação foi a metodologia utilizada por permitir aos pacientes uma participação ativa, em que existe articulação do conhecer e do agir, e, paralelamente ao saber, existe o fazer, não se limitando, portanto, a observar ou medir aspectos aparentes.

\subsection{Procedimento para análise dos dados}

Para a análise dos dados deste estudo, foram utilizados os pressupostos da análise temática preconizada por FREIRE (1992). Esse método é utilizado na alfabetização, que para o autor é antes de mais nada, aprender a ler o mundo, compreender o seu contexto. Com a aplicação do método no presente trabalho, pretendo criar oportunidades para que os pacientes renais crônicos possam desenvolver e aperfeiçoar suas capacidades de "lerem o mundo" em que vivem, composto de hospitais, aparelhos complexos, dietas rígidas e restrição hídrica, vocabulário técnico e profissionais nem sempre acessíveis.

Nesse quadro, o método de PAULO FREIRE, que é ativo, dialogal e crítico, buscou conhecer como os pacientes renais crônicos pensam sua realidade, o que pensam sobre ela, de modo que, ao tomar consciência, sejam criadores de cultura. Assim, trata-se de construir uma educação transformadora, em que o elemento norteador é o diálogo do pesquisador com os sujeitos do estudo, numa relação horizontal. O desenvolvimento prático desse método ocorreu em duas etapas, descritas a seguir:

\section{Primeira etapa: Levantamento do universo temático}

Refere-se ao conjunto de temas geradores, ou seja, à descrição e a interpretação das situações dos pacientes renais crônicos em hemodiálise e a identificação de suas necessidades de aprendizagem e seus conhecimentos prévios. A organização da análise do universo temático seguiu as seguintes fases:

Fase I: Levantamento dos Temas Geradores. Esta fase foi realizada através dos encontros do pesquisador com os pacientes renais crônicos, usando a observação participante durante as sessões de hemodiálise. Pesquisei os temas significativos da vivência destes sujeitos.

Fase II: Organização do Material da Coleta de Dados. Realizei leitura detalhada de todas as observações que foram registradas no diário de campo. É nesta fase que se faz um recorte do texto, selecionando frases ou palavras repetidas com mais freqüência, ou colocadas com mais ênfase pelos pacientes participantes do estudo e que fossem passíveis de serem trabalhadas pelo enfermeiro, na atividade educativa. A seguir, verifiquei o que cada elemento tinha em comum com os outros e os reuni.

Fase III: Seleção e Codificação de Palavras e Frases Registradas Durante as Observações Participantes. Foram selecionadas algumas palavras e frases que tinham sido agrupadas anteriormente pela riqueza temática e estas foram codificadas em temas geradores. 
Fase IV: Síntese das Palavras e Frases Selecionadas. O material foi selecionado e codificado em temas geradores, sendo reagrupadas todas as palavras e frases relacionadas ao tema gerador.

Fase V: Ordem dos Temas Geradores. Os temas geradores foram pedagogicamente ordenados numa seqüência para realização da atividade educativa.

\section{Segunda etapa: A Pesquisa-Ação: Atividade Educativa}

Fase I: Planos de Ensino Relativos aos Temas
Geradores. Nesta fase, foi elaborado um planejamento de ensino, desenvolvido nos Círculos de Discussão, segundo modelo pedagógico de PAULO FREIRE, para cada tema gerador levantado.

Fase II: Desenvolvimento da Educação Conscientizadora. Nesta fase, foi implementado o plano de ensino, iniciando-se com as situações-problema codificadas, para a seguir serem descodificadas*** pelos sujeitos pesquisados e pesquisador. $\mathrm{O}$ debate em torno delas proporcionará ao grupo a conscientização.

\section{EDUCAÇÃO E CONSCIENTIZAÇÃO}

\subsection{Levantamento do universo temático}

\subsubsection{Identificação dos participantes do estudo}

Para identificação dos participantes do estudo, apresento o Quadro1.

\begin{tabular}{|c|c|c|c|c|c|c|c|}
\hline SUJEITO & SEXO & $\begin{array}{l}\text { ESTADO } \\
\text { CIVIL }\end{array}$ & IDADE & ESCOLARIDADE & OCUPAÇÃO & $\begin{array}{c}\text { OCUPAÇÃO } \\
\text { CONJUGE }\end{array}$ & $\begin{array}{l}\text { TEMPO DE } \\
\text { TRATAMENTO } \\
\text { (em anos) }\end{array}$ \\
\hline 1 & $\mathrm{M}$ & $\mathrm{S}$ & $17 a$ & $3^{2}$ série do $1^{\circ}$ grau & - & - & $2 \mathrm{a}$ \\
\hline 2 & $\mathrm{~F}$ & $\mathrm{C}$ & $61 \mathrm{a}$ & $1^{2}$ série do $1^{\circ}$ grau & aposentado & feirante & $2 a$ \\
\hline 3 & $\mathrm{~F}$ & $\mathrm{C}$ & $47 a$ & $1^{2}$ série do $1^{\circ}$ grau & do lar & trabalhador tural & $4 a$ \\
\hline 4 & $\mathrm{M}$ & $\mathrm{C}$ & $63 a$ & $3^{2}$ série do $1^{\circ}$ grau & aposentado & do lar & $2 \mathrm{a} 8 \mathrm{~m}$ \\
\hline 5 & $\mathrm{~F}$ & $\mathrm{C}$ & $48 \mathrm{a}$ & $2^{2}$ série do $1^{\circ}$ grau & do lar & lavrador & $3 a$ \\
\hline 6 & $\mathrm{~F}$ & $\mathrm{C}$ & $43 a$ & $3^{2}$ série do $1^{\circ}$ grau & aposentada & pedreiro & $2 \mathrm{a}$ \\
\hline 7 & $\mathrm{M}$ & $\mathrm{V}$ & $63 a$ & $2^{2}$ série do $1^{\circ}$ grau & aposentado & - & $2 \mathrm{a} 6 \mathrm{~m}$ \\
\hline 8 & M & $\mathrm{C}$ & $57 a$ & $1^{2}$ série do $1^{\circ}$ grau & $\begin{array}{l}\text { afastado do } \\
\text { serviço }\end{array}$ & do lar & $2 \mathrm{a}$ \\
\hline
\end{tabular}

Legenda: M - masculino; F - feminino; S - solteiro; C - casado; V - viúvo

\subsubsection{Levantamento dos temas geradores}

Esta fase, FREIRE (1992), refere ser de resultados muito ricos para os educadores, não só pelas relações que travam, mas pela busca da temática do pensamento dos homens, pensamento este que se encontra somente no meio deles.

Pesquisei os temas significativos para esse grupo de pacientes com IRC, em tratamento hemodialítico, de agosto de 1994 a março de 1995. Esta procura é o ponto de partida do processo de educação do tipo libertador. Como diz FREIRE (1980), o tema gerador é o pensamento do homem sobre a realidade e sua ação sobre esta realidade, que está em sua práxis.

Essas observações aconteceram durante as sessões de hemodiálise e duravam em média 4 horas cada. Conforme recomenda TRIVIÑOS (1987) em relação às anotações de campo, foram registrados, no diário, manifestações verbais, ações dos pacientes, ambiente fisico e reflexões do observador.

\subsubsection{Organização do material recolhido}

O conteúdo registrado através de observação participante foi interpretado e dele, selecionados os assuntos centrais, segundo sugere FREIRE (1992). É realizada a escolha das palavras e frases registradas com muita freqüência e passíveis de serem trabalhadas pelo enfermeiro na atividade educativa. A seguir, reuni essas palavras e frases sob os mesmos temas.

\footnotetext{
*** Descodificação - é análise crítica da situação existencial codificada, feita pelos educandos e educadores, levando os educandos a conscientizarem à medida que se alfabetiza (FREIRE, 1980)
} 
5.1.4. Seleção e codificação de palavras e frases, registradas durante as observações participantes

Sem ordem definida, foram selecionadas e codificadas as frases registradas durante as observações participantes, originando os temas geradores. Assim, por exemplo:

- "O médico explicou que a minha salvação era o transplante renal". $\rightarrow$ Transplante renal

- "Será que não é possível o rim voltar a funcionar?" $\rightarrow$ Desinformação sobre a Insuficiência Renal Crônica

\subsubsection{Síntese das palavras e frases selecionadas}

O material selecionado das observações foi reunido em grandes temas, como:

Insuficiência Renal Crônica.

- "...O que é minha doença?"

-“... eu urino, como o rim não funciona?"

-“... não tem remédio que cura?”

\subsubsection{Ordens dos temas geradores}

Os temas geradores foram levados, por serem de interesse dos pacientes e terem sido várias vezes relatados, os quais foram colocados em uma ordem pedagógica: Insuficiência Renal Crônica, depois Causas da IRC, o tratamento hemodialítico, as suas limitações e as suas possibilidades, o transplante renal e, por último, o apoio da família.

\section{A PESQUISA-AÇÃO: ATIVIDADE EDUCATIVA}

\subsection{Planos de ensino relativos aos temas geradores}

O plano de ensino, elaborado para cada tema gerador, iniciava-se sempre com uma situação problematizadora e motivadora de discussões, como figuras, cartazes, perguntas e verbalização de experiências significativas. Após essa fase, os pacientes extraíam os pontos-chave que eram analisados por eles e pelo pesquisador.

Organizava-se e explicava-se esses pontos-chave, correlacionando-os com suas situações, solicitando que verbalizassem soluções aplicáveis à realidade de cada um.

Essa fase, para FREIRE (1992), consiste na elaboração de plano de ensino para auxiliar o coordenador do debate no seu trabalho educativo, mas destaca que deve ser um subsídio e jamais uma prescrição rígida a que se deve obedecer. A título de exemplo, apresento, a seguir, um plano de ensino de um dos temas geradores dos pacientes em estudo.

\section{PLANO DE ENSINO}

\section{Tema I: Insuficiência Renal Crônica (IRC)}

Duração Aproximada: 1 hora e 30 minutos

Participantes: 8 pacientes e 1 coordenadora

\begin{tabular}{|c|c|c|c|c|}
\hline OBJETIVOS & CONTEÚDOS & ESTRATÉGIAS & RECURSOS & AVALIAÇÃO \\
\hline $\begin{array}{l}\text { Objetivo Geral } \\
\text { O grupo de pacientes } \\
\text { deverá ser capaz de: } \\
\text { compreender a IRC, suas } \\
\text { causas e as } \\
\text { consequências desta em } \\
\text { sua vida. } \\
\text { Objetivos específicos } \\
\text { 1. Descrever de forma } \\
\text { genérica a I.RC. } \\
\text { 2. Identificar o impacto } \\
\text { da Insuficiência Renal } \\
\text { Crônica na vida do } \\
\text { paciente. }\end{array}$ & $\begin{array}{l}\text { 1. Noções sobre } \\
\text { anatomia e fisiologia do } \\
\text { sistema urinário e } \\
\text { noções gerais da I.R.C. } \\
\text { 2. Impacto daI.R.C. para } \\
\text { o seu portador. }\end{array}$ & $\begin{array}{l}\text { 1. Desafio ao grupo: } \\
\text { (mostrar peças } \\
\text { anatôtmicas do sistema } \\
\text { urinário). } \\
\text { 2. Aula expositiva } \\
\text { dialogada(usar "slides" } \\
\text { para dar noções de } \\
\text { fisiologia renal). } \\
\text { 3.Discussão em comum } \\
\text { (perguntar o que } \\
\text { significou o início do } \\
\text { tratamento e solicitar } \\
\text { que o grupo discuta o } \\
\text { impacto da I.R.C. para } \\
\text { suas vidas). }\end{array}$ & $\begin{array}{l}\text { 1. Peças anatôtricas do } \\
\text { sistema urinário (rins, } \\
\text { bexiga, uretra). } \\
2 . \text { "slides". } \\
3 . \text { quadro negro e giz. }\end{array}$ & $\begin{array}{l}\text { Ao final da unidade, o } \\
\text { grupo poderá verbalizar: } \\
\text { 1.O conceito de I.R.C. } \\
\text { 2. A descrição do } \\
\text { impacto daI.R.C. em sua } \\
\text { vida. } \\
\text { Após } 2 \text { meses, será } \\
\text { realizada observação } \\
\text { em campo pela } \\
\text { coordenadora, para que } \\
\text { verifique a } \\
\text { compreensão da IRC } \\
\text { pelos pacientes. }\end{array}$ \\
\hline
\end{tabular}

Obs.: as frases entre aspas são falas dos pacientes renais crônicos em tratamento hemodialítico e as frases antecedidas por uma flecha $(\rightarrow)$ constituem os temas geradores 
7. RESULTADOS E DISCUSSÃO

Apresentarei a análise do trabalho desenvolvido com o grupo, discutindo o desenvolvimento dos temas.

\section{Tema I: Insuficiência Renal Crônica}

Iniciei com apresentação das peças anatômicas do sistema urinário. Quando viram pela primeira vez o rim, começaram a perguntar sobre a sua localização, coloração e a fisiologia renal. Percebi que muitos o pegaram para conhecer sua consistência, a fim de compreender melhor. Tinham necessidade de palpar, além de ver, algo de que até então só tinham ouvido falar. Era muito vago, queriam algo mais, queriam algo concreto. Com a visualização e a palpação do rim, ficou mais fácil discutir sobre a coloração, o tamanho e as funções.

Quando perguntei sobre as funções do rim, verbalizaram o seguinte: "Filtra a sujeira do sangue". A função de filtração foi a única que descreveram. Desconheciam as outras, mas, após informações, conseguiam associá-las aos problemas que apresentavam.

Após as informações sobre a fisiologia renal, discutimos sobre a insuficiência renal crônica quanto à definição e às suas fases. Cabe ressaltar que a fase urêmica foi lembrada claramente, quando expressaram: "coma" "falava besteira", "tinha soluço". As outras fases passaram desapercebidas para a maioria dos pacientes.

Solicitei que o grupo descrevesse e discutisse o impacto da doença e do tratamento em suas vidas. Evidenciei que o grupo refere que a doença e o tratamento surgiram de forma abrupta e inesperada. Lembram com detalhes quando o médico anunciou o seu diagnóstico ou quando iniciaram o tratamento dialítico.

Os pacientes relataram, com muita tristeza, as mudanças geradas pela doença e o tratamento, como: "mudou tudo"; "não dá pra ir pra canto nenhum"; "agora quem manda em casa é a patroa"; "aposentadoria é uma miséria"; "quem dá emprego pra uma pessoa que faz hemodiálise?".

Ao final da discussão, foi realizada a avaliação do conteúdo proposto, através de perguntas, às quais o grupo respondeu. Em relação ao assunto Insuficiência Renal Crônica, receberam informações sobre o que faltava conhecimento e questionaram no sentido de um melhor esclarecimento. $\mathrm{O}$ grupo conseguiu, por meio das informações oferecidas, compreender a anatomia, a fisiologia renal, a insuficiência Renal Crônica. E a discussão sobre o impacto da doença e do tratamento foi importante. O compartilhar, com o grupo todo, as mudanças que ocorrem, a troca de experiências de como cada um reagiu frente a essa realidade é de grande importância para suas vidas. Neste sentido, um paciente relata: "Isso é bom, saber que não é só eu que penso assim".

O grupo conseguiu descrever, de uma maneira geral, a IRC, e que o esclarecimento de anatomia e fisiologia renal facilitou a compreensão da doença. Identificaram também o impacto da doença, como BARBOSA(1993) descreve que essa brusca mudança no seu viver é marcante para o doente renal crônico.

\section{Tema II: Causas da Insuficiência Renal Crônico (IRC)}

Para iniciar essa reunião, três cartazes sugestivos de diabetes, calculose renal e hipertensão arterial foram fixados no quadro negro. Essas doenças foram causadoras da IRC dos integrantes do grupo, por essa razão não foram discutidas outras causas.

O grupo identificou o primeiro cartaz da hipertensão arterial, depois da calculose renal e por último da diabetes. Relacionou as doenças que levaram à IRC: "O meu problema foi pressão alta..."; “...foi pedra no rim..."; “...tinha diabetes...”. E fizeram vários questionamentos sobre a doença. Ao final, foram avaliados verbalmente os tópicos abordados.

A partir da visualização dos cartazes, o grupo relacionou o assunto com sua realidade e com comportamentos capazes de prevenir a IRC, elaborando sugestões para a prevenção. Cada membro do grupo conseguiu relacionar a doença que causou sua IRC. As doenças que foram discutidas, ficaram esclarecidas, pois utilizei de cartazes para iniciar as discussões e chegar à problematização do tema, o que, para FREIRE (1992), significa procurar novas compreensões de novos desafios.

\section{Tema III- Tratamento Hemodialítico}

Foram apresentados materiais utilizados no tratamento hemodialítico e o grupo foi indagado sobre o que eram e qual a sua finalidade. Por conviverem, três vezes na semana com objetos e vocabulário técnico da hemodiálise, souberam descrever a função de cada objeto, mas apresentaram desconhecimento dos nomes de alguns materiais, e alguns questionamentos.

Para esclarecer sobre o funcionamento da hemodiálise, foi solicitado ao grupo que demonstrasse o tratamento, numa dramatização em que cada integrante do grupo representasse um elemento da hemodiálise.

Perguntei ao grupo quais os problemas durante ou após o tratamento e identificaram algumas intercorrências mais comuns, durante ou após hemodiálise, como: hipotensão arterial, vômitos, cãibras, cefaléia, malestar, relataram as medidas de prevenção e intervenção de cada intercorrência. Na parte final da discussão, foi 
realizada a avaliação do conteúdo proposto, através de perguntas, a que o grupo respondeu de forma ordenada.

A metodologia conscientizadora facilita a intervenção do profissional de maneira adequada, porque considera os conhecimentos, as percepções, as dúvidas e as necessidades dos pacientes. Percebo, na prática, que os pacientes que realizam o tratamento hemodialítico apresentam sobre ele, muitas fantasias, ou mesmo falta de conhecimento, como demonstraram durante o desenvolvimento desse tema gerador.

Nesta perspectiva, ANGER (1975) relata as fantasias dos pacientes renais crônicos relacionadas à máquina e à imagem do corpo, como se fossem "homens semi-artificiais". Tais pacientes, que ficam uma parte da semana em suas casas, e a outra na unidade de hemodiálise, necessitam de profissionais com habilidades, conhecimentos e capazes de um bom relacionamento, para auxiliá-los.

\section{Tema IV: Possibilidades e Limites do Paciente com IRC em Hemodiálise}

Para iniciar essa reunião, foram apresentados dois cartazes: um com figuras de alimentos proibidos e outro de alimentos importantes na dieta dos pacientes. Depois, foi solicitado aos membros do grupo que identificassem as figuras e falassem se poderiam comer à vontade ou com restrição. Entreguei para todos integrantes do grupo, o manual sobre alimentação dos pacientes renais crônicos que eu mesma elaborei e esclareci alguns questionamentos relativos à dieta, à restrição do sal. $\mathrm{O}$ grupo relatou suas experiências quanto à dieta alimentar.

Após, discutiu-se sobre o controle hídrico. Primeiramente, cada integrante relatou como controla a ingestão hídrica. Notou-se que havia falta de conhecimento sobre o quanto poderiam ingerir de líquido, e isso foi esclarecido. Discutiu-se também as atividades físicas possíveis e as impossíveis, ocorrendo assim, a troca de experiências. Muitas sugestões foram apresentadas pelo grupo para aplicação a sua realidade - situação econômica e cultural do paciente e sua família - de modo a obter melhor qualidade de vida, mesmo com as limitações causadas pela doença.

\section{Tema V: Transplante Renal}

Iniciou-se com o relato de experiências de dois transplantados, - um que obteve sucesso e outro que teve rejeição, - e do doador do órgão rejeitado. O grupo indagou dos transplantados e o doador, quanto aos exames, à cirurgia, à anestesia, à recuperação, e a outros aspectos considerados importantes no transplante renal.
Os membros do grupo descreveram experiências significativas de transplante renal e discutiram as dificuldades para a realização deste. Após, foi apresentado um filme de transplante renal, próprio para os pacientes, para tomarem conhecimento do que ocorre no procedimento cirúrgico.

Foi solicitado ao grupo que elaborasse um desenho simbolizando para eles, o transplante renal. O grupo apresentou o desenho de uma estrela, descrevendo a importância do transplante renal como "esperança"; "brilho"; "paz"; "vida nova". Ao final da discussão, o grupo manifestou sugestões para agilizar a realização do transplante renal.

O grupo definiu transplante renal, mostrou compreensão do que ocorre nos períodos pré-trans-pós operatório, e referiu os problemas mais comuns que dificultam a realização do procedimento. Aqueles que não possuem doadores vivos, esperam por um doador cadáver, mas sabem que existem várias pessoas aguardando na fila de espera de um rim; sugeriram formas de esclarecimento a população, sobre a doação de orgãos.

ROMÃO JUNIOR(1995) refere que o melhor tratamento para a IRC é sem dúvida o transplante renal, que só não poderá ser realizado em casos de neoplasia, infecções sistêmicas em atividade, incompatibilidade sanguinea $\mathrm{ABO}$ e presença de anticorpos citotóxicos préformados contra o doador.

\section{Tema VI: Apoio da Família}

Para iniciar essa reunião, uma figura sugestiva de família foi colocada no quadro negro. O grupo identificou como tal e relacionou-a com suas famílias, e expressou o apoio recebido ou não de seus familiares.

Trouxeram para a discussão, as experiências de apoio familiar, e a falta deste, revelada em frases como: "não me acompanha", "tem família que acompanha até o portão de casa, a minha nem isso não faz", "a minha família passa uma raiva danada", "tenho que me virar sozinha". De todos os pacientes, apenas dois se declararam apoiados pela família. Diante da falta de apoio dos familiares, coloquei-me à disposição, se achassem que poderia ajudá-los, mas preferiram primeiro tentar solucionar o problema por si mesmos, conversando com os membros da família, esclarecendo-os sobre a doença e o tratamento.

Quanto ao transplante, os participantes do grupo querem se reunir e fazer algo para mudar essa situação, como esclarecimento ao público. Sugeriram também, que o trabalho educativo fosse estendido aos familiares, o que seria uma forma de conscientizá-los e sensibilizá-los.

Os familiares contam que os pacientes compartilharam as informações recebidas, explicaram o 
manual de restrição hídrica e alimentar, mas não compartilham os seus problemas emocionais, como se a doença fosse um problema apenas do paciente e não de suas famílias, talvez procurando poupá-las de situações difíceis.

Para FREIRE(1980), a transformação do modo de pensar significa a tomada de consciência do mundo, a percepção que o homem adquire de si e de sua realidade histórica. Verificou-se que após a experiência educativa, o grupo em estudo começou a "desvelar"a sua situação; ocorrendo portanto, mudanças que alteram suas atividades e comportamentos.

\section{CONSIDERAÇÕES FINAIS}

Nos últimos anos, como conseqüência do avanço técnico-científico e da utilização de equipamentos sofisticados no tratamento hemodialítico, tem-se fortalecido a competência profissional do enfermeiro nas tarefas de observar, interpretar, realizar, decidir e avaliar. No entanto, com freqüência as atividades educativas são negligenciadas. Entendo que, na procura da excelência da assistência de enfermagem ao paciente renal crônico em tratamento dialítico, é necessário que o enfermeiro tenha, além da fundamentação científica e de competência técnica, também o conhecimento dos aspectos que levem em consideração os sentimentos e as necessidades de tais pacientes. Neste contexto, o enfermeiro deve estabelecer diálogo com os pacientes, ultrapassando o formalismo técnico habitual, de fornecer informações frias, de difícil compreensão, estanques, no momento errado, e onde praticamente só o profissional tem a palavra e a razão.

Levantar previamente os conhecimentos e as experiências do paciente renal crônico, facilitou a compreensão das reais necessidades de aprendizagem desses pacientes e, também, a adoção da melhor estratégia e do mais adequado conteúdo para implementar uma ação de intervenção eficaz do enfermeiro.

Esta constatação me leva a acreditar que as ações educativas desenvolvidas com aplicação da metodologia conscientizadora, entre pacientes renais crônicos em tratamento hemodialítico, proporcionaram reflexão e compreensão dos elementos básicos quanto à realidade da doença e dos esquemas terapêuticos utilizados. $\mathrm{O}$ próprio método de investigação, a pesquisa-ação, pressupõe uma relação de participação entre sujeitos e pesquisadores. Juntos refletem e procuram elucidar os problemas.

Considerando os resultados, julguei oportuno apresentar as modificações ocorridas na realidade do grupo de pacientes renais crônicos submetidos a sessões de hemodiálise e participantes dos Círculos de Discussão.

Foi possível identificar que os pacientes renais crônicos inseridos no grupo tinham dificuldade na compreensão e interpretação das orientações fornecidas pelos profissionais de saúde. Depois da implementação do plano de ensino, percebi que muitas de suas dúvidas foram sanadas e que se não compreendiam as explicações que eram "passadas" para eles, anteriormente, era porque estas se apresentavam muito abstratas, distantes de sua realidade. Esta constatação está reiterada nas solicitações emitidas pelos participantes do estudo, para que outros pacientes, como eles, tivessem a oportunidade de discutir os temas geradores.

Outras manifestações verbais dos pacientes refletem a eficácia das ações educativas implementadas. Os pacientes do grupo passaram a fazer questionamentos sobre a quantidade de heparina administrada, as intercorrências durante e após hemodiálise, a finalidade e os resultados dos exames e quanto ao seu peso seco. Passaram ainda a controlar melhor o ganho de peso e a seguir a dieta adequada.

Foi interessante perceber que, a partir dessa experiência educativa, os pacientes inseriram em seu repertório, e utilizavam o vocabulário médico utilizado na situação de hemodiálise,como "set arterial", "set venoso", "cata-bolha", "compatível", "hematócrito", "glóbulos vermelhos", "insuficiência renal crônica", entre outros.

O grupo tenta esclarecer as dúvidas dos colegas e, a partir desta etapa, está questionando a atuação da equipe de saúde. Tal fato, inclusive, provocou reação negativa da equipe, que passou a incomodar-se com a participação do grupo, considerando-o "chato", "implicante", "intrometido". Entende-se que a equipe de saúde tem dificuldade em interagir com os pacientes, pois no ambiente hospitalar, a equipe é que detém o controle da condição do paciente e costuma atuar "impondo as regras do jogo".

Pela razão acima, justifica-se a necessidade premente de trabalhar com a equipe, para que leve em consideração, no seu cotidiano do trabalho, as necessidades dos outros que estão sob seus cuidados profissionais. Então, é preciso que alterem as condutas usuais na assistência aos pacientes.

Os pacientes relataram a compreensão do transplante renal, assunto esse de maior interesse demonstrado pelo grupo. Os pacientes formaram um grupo operativo de renais crônicos, que foi denominado Associação dos Pacientes Renais Crônicos (APREC) de São José do Rio Preto-SP, a fim de discutirem suas necessidades, e lutarem pela agilização do transplante renal nas Unidades Hospitalares da cidade.

Quanto ao apoio familiar, as falas dos pacientes 
indicam ter melhorado o relacionamento com os seus familiares, mas alguns ainda reclamam um apoio maior. Conversei com os familiares, os quais relataram mudança de comportamentos dos pacientes no domicílio, considerando-os mais dispostos, mais calmos, com melhor relacionamento social e maior atenção as ações de cuidado necessárias.

É importante destacar que não se pretende, com este estudo, esgotar o assunto e nem buscar "soluções prontas" para o paciente renal crônico em tratamento hemodialítico. Pretendo, sim, contribuir para a atividade educativa dos enfermeiros, na busca de uma melhor compreensão do paciente renal crônico e conseqüentemente, de um processo de ensinoaprendizagem que permita o desenvolvimento de uma consciência crítica desses pacientes, criando condições para uma intervenção transformadora dessa situação, visando a melhoria na sua qualidade de vida.

Então, com esse trabalho, reitero meu propósito de contribuir para o desenvolvimento da enfermagem e de oferecer subsídios para o ensino, a prática e pesquisas relacionadas ao paciente renal crônico em tratamento hemodialítico e, sobretudo, para proporcionar a tais pacientes não uma prática de orientação prescritiva, autoritária, mas uma educação libertadora, dentro da realidade dos participantes.

\section{CHRONIC RENAL PATIENTS IN HEMODIALYTIC TREATMENT: NURSE'S EDUCATIVE ACTION}

The aim of this study is to contribute to the knowledge of the nurse's educative activity with chronic renal patients undergoing an hemodialytic treatment, providing an improvement in the patient's quality of life and using a model called "awareness education". The subjects of this study were eight chronic renal patients - four female patients and four male patients whose age varied from 17 to 63 years old. The methodological approach was the research-action and data collection about significant situations was carried out through participant observation. Data interpretation was related to the referential proposed by PAULO FREIRE, i.e. the analysis of the generating themes. Data were selected and encoded in six generating topics: Chronic Renal Failure (IRC), Causes of IRC, Hemodialytic Treatment, Chronic Renal Patient's Limitations and Possibilities when undergoing an Hemodialytic Treatment, Renal Transplantation and Family Support. The Discussion Groups were developed according to the Pedagogical Method by PAULO FREIRE. After that stage, satisfactory changes in the chronic renal patients' quality of life who participated in the teaching-learning process have been observed. This has enabled us to conclude that there has been a development of the naïve consciousness for the criticism about their situation, owing to some changes in their reality.

KEY WORDS: nursing, education, hemodialysis

\section{PACIENTE CON INSUFICIENCIA RENAL CRÓNICA EN TRATAMIENTO HEMODIALÍTICO: ACTIVIDAD EDUCATIVA DEL ENFERMERO}

El objetivo de este estudio fue contribuir para el conocimento de la actividad educativa del enfermero con el paciente renal crónico en tratamiento hemodialítico, proporcionando mejoría de su calidad de vida, a través de la educación cocientizadora. Los individuos de ese estudio fueron ocho pacientes renales crónicos, cuatro del sexo femenino y cuatro del sexo masculino con edad entre 17 y 63 años. La trayectoria metodológica consistió en obtener datos sobre situaciones significativas usando la observación participante. La interpretación de los datos se relacionó con el sistema propuesto por PAULO FREIRE, o sea, el análisis de los temas generadores. Los datos fueron seleccionados y codificados en seis temas generadores: Insuficiencia renal crónica (IRC). Causas de la IRC, Tratamiento Hemodialítico, Limitaciones y posibilidades del renal Crónico en tratamiento Hemodialítico, Transplante Renal y apoyo familiar. Los Círculos de Discusión se desarrollaron según el Método Pedagógico de Paulo Freire. Después de esa fase, se verificaron cámbios satisfactorios en la calidad de vida de los pacientes renales crónicos participantes del proceso enseñanza-aprendizaje. Eso permitió concluir que hubo una evolución de la conciencia ingénua para la conciencia crítica en relación con su situación, pues ocurrieron transformaciones en su realidad.

TÉRMINOS CLAVES: enfermería, educación, hemodiálisis

\section{REFERÊNCIAS BIBLIOGRÁFICAS}

01. ANGER, D. The psicologic stress of chronic renal failure and long-term hemodialysis. Nurs. Clin. North. Am., v.10, n.3, p.449-60, 1975.
02. BARBOSA, J.C. Compreendendo o ser doente renal crônico. Ribeirão Preto, 1993. 144p. Dissertação (Mestrado) - Escola de Enfermagem de Ribeirão Preto, Universidade de São Paulo.

03. CHIZZOTI, A. Pesquisa em ciências humanas e sociais. São Paulo: Cortez, 1991. 164p. 
04. DOMINGUES, J.L. O cotidiano da escola de $\mathbf{1}^{\mathbf{0}}$ grau - o sonho e a realidade. São Paulo, 1985. 200p. Tese (Doutorado) - Pontifícia Universidade Católica de São Paulo.

05. FREIRE, P. Conscientização: teoria e prática da libertação - uma introdução ao pensamento de Paulo Freire. Trad. de Kátia de Mello e Silva. 3ed. São Paulo: Moraes, 1980. 102p.

06. FREIRE, P. Educação como prática da liberdade. 21.ed. Rio de Janeiro: Paz e Terra, 1992. 158p.

07. Pedagogia do oprimido. 22 ed. São Paulo: Paz e Terra, 1993. 184P.

08. GORRIE, S. Patient education: a commitment. ANNA J., v. 19, n.5, p.504-6, 1992.

09. LIMA, E.B. Opinião do paciente com insuficiência renal crônica, submetido à técnica de autoadministração de medicamentos orais durante a hospitalização. São Paulo, 1989.72p. Dissertação (Mestrado) - Escola de Enfemagem de São Paulo, Universidade de São Paulo.
10. MINAYO, M.C.S. O desafio do conhecimento: pesquisa qualitativa em saúde. 3 ed. São Paulo/ Rio de Janeiro: HUNITEC/ABRASCO, 1994. $269 \mathrm{p}$.

11. PHILLIPS, H. et al. The role of the nurse as a teacher: a posicion paper. Nephrol.Nurs., v. 5, p. 42-6, 1983.

12. ROMÃO JUNIOR, J.E. Insuficiência renal crônica. In: CRUZ,J.; PRAXEDES, J.N.; CRUZ,H.M.M. Nefrologia. São Paulo: Sarvier, 1995, p. 187-200.

13. THIOLLENT, M. Metodologia da pesquisa-ação. 4 ed. São Paulo: Cortez, 1988. 108p.

14. TRIVINÕS, A.N.S. Introdução à pesquisa em ciências sociais: a pesquisa qualitativa em educação. São Paulo: Atlas, 1987. cap. 5, 11673: pesquisa qualitativa. 